\title{
'VIDA DE ESCOLA': EDUCAÇÃO E COMUNICAÇÃO NA REDE DE ESCOLAS DE SAÚDE PÚBLICA BRASILEIRA
}

SCHOOL LIFE: EDUCATION AND COMMUNICATION IN BRAZILIAN PUBLIC SCHOOLS NETWORK

\author{
Caco Xavier ${ }^{1}$ (iD) (0000-0003-4982-5399) \\ ${ }^{1}$ Fundação Oswaldo Cruz, Escola Nacional de Saúde Pública Sergio Arouca, Rio de Janeiro, RJ, Brasil. \\ $<$ caco.xavier@gmail.com>
}

Resumo O objetivo foi buscar as relações entre conceitos caros à educação, tomando por base a interseção entre os campos profissionais da educação, da comunicação e da gestão voltados para a saúde pública. Para tornar possíveis tais sínteses, investe-se na criação do conceito de 'vida de escola', por meio de documentos e atividades no âmbito da rede de escolas de saúde pública brasileira, em que essa expressão teria surgido, à espera de definições e vizinhanças adequadas. Por meio desse conceituário, discutem-se alguns dos aspectos e mediações mais fundamentais às concepções modernas de educação e ao papel das escolas de saúde em nosso país.

Palavras-chave educação; educação em saúde; comunicação; formação para saúde pública.
Abstract This paper aimed to highlight the relationships between concepts dear to education, based on the intersection between the professional fields of education, communication and management focused on public health. To make such syntheses possible, we invest in the creation of the concept of 'school life', going back to the documents and activities within the Brazilian Public Health School Network, where this expression would have emerged awaiting definitions appropriate and neighborhoods. Through this concept, we discuss some of the most fundamental aspects and mediations to modern conceptions of Education and the role of health schools in our country.

Keywords education; health education; communication; public health formation. 


\section{Introdução}

Este artigo é um ensaio, não somente em seu sentido formal de modalidade narrativa. Trata sobre a criação de um conceito ('vida de escola') - um ensaio teórico, portanto - e sua incidência sobre as relações potenciais entre os campos da comunicação, da educação e, ainda que de raspão, da gestão. Nas primeira e segunda partes do texto, ocupo-me do mapa e das rotas do conceito (sua geografia, uma toponímia, suas direções e linhas de fuga); no terço final, desenho as camadas circundantes (convergentes e divergentes) desses grandes continentes que, diz-se, em tempos míticos teriam conformado uma única pangeia (uma única paideia), formidável ilha habitável.

Em todas as etapas dessa empresa, os limites e restrições são tamanhos que, por pouco, não chegam a comprometer todos os esforços. Por um lado, fala-se de uma 'escola' e de uma 'educação' que talvez não expressem de modo adequado ou suficiente as necessidades e o espírito desse tempo. Ao referir-me a tais ambientes, eu o faço perfeitamente ciente de que esse discurso se parece com o do astrônomo que estuda o brilho das estrelas mirando o passado na luz que se mostra 'presente'.

Falo, portanto, de uma (ideia de) escola e educação de nossos avós e pais, e não daquelas que (de)vêm incessantemente e a cada vez por modos ainda mais céleres. Falamos de uma espécie de educação que remonta a meros duzentos anos da história humana, inspirada, por um lado, pelos ideais do Iluminismo (educação fundada no primado da razão) ${ }^{1}$ e, por outro, pelas necessidades emergentes da Revolução Industrial (educação moldada pelos motores do trabalho e do capital). Isto é, falo de uma educação estritamente moderna e ocidental, para o bem ou para o mal.

Ainda que eu mantenha em presença os processos educativos resultados das reflexões e críticas de (por exemplo) Edgar Morin e suas cabeças bem-feitas (2004), Boaventura Santos e sua ecologia dos saberes $(2004,2007)$ e, mais recentemente, Michel Serres e sua Polegarzinha (2013), estes aparecem como equações matemáticas a nos lembrar que o astro brilhante que vemos pode muito bem ter já se tornado um imenso buraco negro no instante mesmo em que o fotografamos.

Nesse caso, somos confrontados a todo instante pelo fato sobejamente conhecido de que, em relação às humanidades, as pretensões de futuro estão sujeitas a erros de rota irreparáveis. Lembro, sobretudo, o óbvio que teima em estar sempre oculto (et pour cause) de que qualquer epistemologia é necessariamente humana e que até mesmo tal perspectiva ('humanista') encontra-se há muito sob suspeita, graças aos trabalhos de, entre outros, Richard Ryder (1975) e Peter Singer (2004). ${ }^{2}$

Por outro lado, este ensaio deve lidar com um paradoxo (ou, para não sermos tão dramáticos, com um paroxismo) de difícil transposição. O exercí- 
cio teórico de tentar entender a escola viva e os processos educativos parece uma reencenação da Lição de anatomia do Dr. Tulp (Figura 1): categorizamos, separamos, dissecamos elementos de um sistema orgânico e vivo. No entanto, o único modo de fazê-lo (em épocas em que não havia tecnologias de tomografia computadorizada) era abrir um corpo morto. Embora a comparação pareça um tanto mórbida, ela soa-me adequada a um tal exercício, quiçá a qualquer exercício teórico que seja, uma vez que a realidade, "sempre irregular", dinâmica e viva, "é ocultada pela simetria dos conceitos" e suas ilusórias fronteiras e partições (Paz, 1996, p. 122).

Figura 1

Lição de anatomia do Dr. Tulp - Rembrandt (1632)

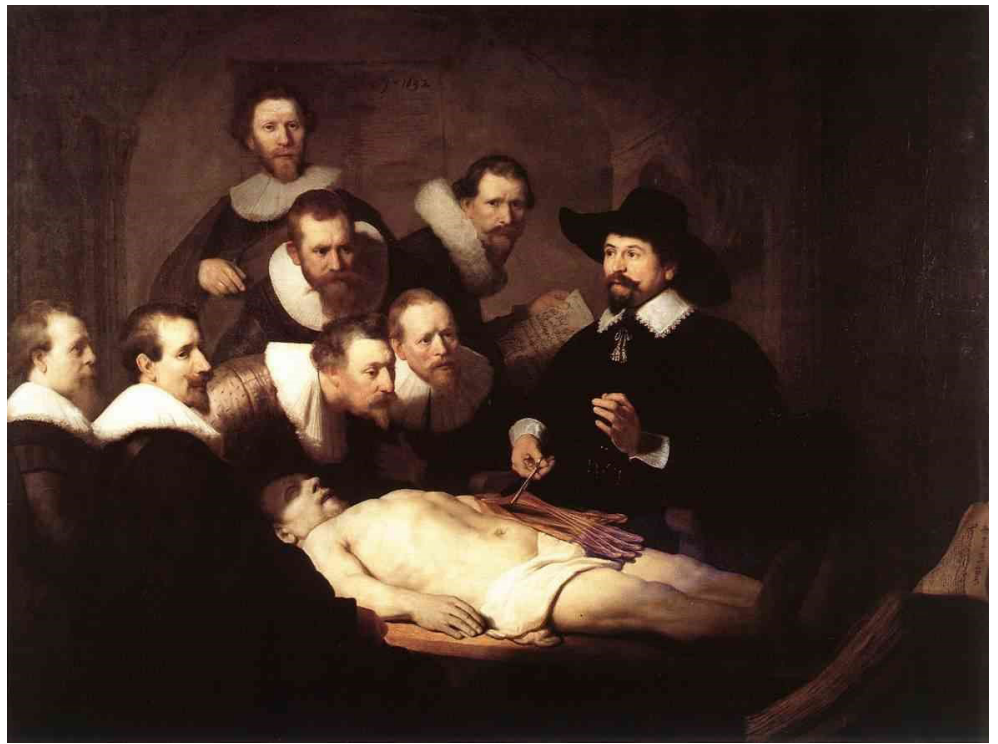

Assim, para entendermos a 'escola', vemo-nos forçados a nos debruçar sobre um corpo no qual o sangue não corre, o alento não infla o peito e os músculos não se movem. O que nos resta é um corpo teorético, um 'corpo em tese', segundo o qual buscamos - como um astrônomo - supor o que agora é a partir do que foi um dia ou - como um geômetra - esboçar e produzir reduzidos esquemas ideais de pontos e linhas que representem (estejam para) um território imenso e complexo. Em relação aos grandes continentes (educação e comunicação, principalmente), o paroxismo é ainda mais verdadeiro, uma vez que atualmente é possível (e irresistivelmente necessário) questionar o estatuto delimitado de tais campos de conhecimentos e práticas profissionais. Nossa atuação possível em relação àquelas grandes áreas, por sua intangibi- 
lidade e alto grau de abstração, assemelhar-se-ia à vivissecção de fantasmas. Isto, naturalmente, só seria possível como ficção... ou anedota.

Diante desse quadro, como prosseguir, então? E, antes de tudo, para que serviriam os esforços envidados em um ensaio como este? Adianto a resposta à segunda parte da questão, oferecendo duas possibilidades. Em primeiro lugar, entendo que uma compreensão do conceito de vida de escola e das relações entre a educação, a educação e a gestão (ainda que esta de raspão) nos ofereça vias de saída para as aporias em que nos metemos (ou fomos metidos, ou ambos) nesses tempos de excessos precários, ${ }^{3}$ da hybris complexa das tecnologias de informação e comunicação e, consequentemente, do intenso (mas difuso) sofrimento moral que atravessa nossas sociedades. Culpa (?) da (falta de) 'educação'? Quem saberia dizer? Tais 'saídas' assemelhar-se-iam mais a caminhos não trilhados (que podem ou não dar em lugares mais interessantes dos que os nossos velhos conhecidos) do que a destinos precisos. Que viver é de todo impreciso, ${ }^{4}$ como dizia, torcendo o senso, o poeta quattrocento.

Em segundo lugar, trata-se de um ensaio reflexivo, e o próprio exercício da crítica já traz, em si, um benefício: ao laborar sobre as possibilidades do erro e do equívoco, fortalece-se o aparelho coletivo de pensar-com, de contaminação (e produção!) do acidente e, enfim, oferecem-se condições a mudanças, ainda que não já, ainda que não pelos meios previamente figurados, ainda que não (melhor que não seja) por nós mesmos.

Mas a questão permanece: como prosseguir? Adoto, apenas de início e na falta de melhor aposta, a suspensão de uma criança que brinca. 'Como se' este bonequinho inerte em minhas mãos (em minhas palavras) fosse vivo, e falasse, e se movesse. 'Como se' estivesse de fato sujeito às regras que imponho e prescrevo, e adivinho e invento para que fale e aja. 'Como se' eu mesmo fosse um deusinho olímpico a observar do alto (intervindo pouco, e quase sempre por capricho) as ações comuns e humanas. Mas não é esse o estatuto original daquilo que temos chamado reverentemente de 'teoria'?

\section{Vida de escola e o conceito de conceito}

A expressão 'vida de escola' tornou-se corrente no âmbito de uma pesquisa realizada em 2007 pela Escola Nacional de Saúde Pública Sergio Arouca (Ensp) da Fundação Oswaldo Cruz. Integrante do Projeto RegeSUS, convênio entre a Ensp e o Ministério da Saúde, a pesquisa envolveu 18 escolas e centros formadores em saúde pública do Brasil. Desse modo, 'vida de escola' aparece no relatório final da pesquisa (Brasil, 2008, p. 26) identificando as diferentes dimensões institucionais de uma escola, "tudo aquilo que dela faz parte, sejam sua estrutura, suas atribuições, a forma como é organizada e gerida, suas relações, limitações, potencialidades e desafios".

Segundo o documento, a escolha desse termo, tomado como referência e guia para a construção dos instrumentos de desenvolvimento da pesquisa de 
campo e pano de fundo da investigação, teria fundamento na própria "visão multifacetada da escola, (n)o caráter dialético de suas funções, (n)a atenção às demandas da sociedade e (n)a necessidade de construir novos olhares ao fenômeno educativo" (Brasil, 2008, p. 15).

Ainda assim, o termo carecia perceptivelmente de um caráter conceitual um pouco mais preciso, de modo a ser utilizado à larga em outras instâncias e para outros fins além daquela investigação restrita. Ou seja, tratava-se de uma ideia-força e não, ainda e propriamente, de um conceito - com intensão, extensão, vizinhanças e (des)limites, como estabelecido nas lições de Kant (1982). No entanto, o que nos moveu a ensaiar esse percurso - nesse sentido, a conformação do conceito 'vida de escola' - foi o entendimento de que, se por um lado, tal expressão naturalizou-se em nossas conversas e debates institucionais, nos círculos próximos à Secretaria Executiva da Rede de Escolas e Centros Formadores, localizada na Ensp, mas utilizada de modo frouxo e com uma variedade de sentidos que chegava a causar certos ruídos de comunicação; por outro, apesar dessa imprecisa e difusa utilização, estava claro que 'vida de escola' soava como uma grande potência significativa, cujas possibilidades de apropriação e uso pareciam ainda longe de ser plenamente figuradas.

Por fim, um último e decisivo 'empurrão' no sentido de precisar, afinal de contas, sobre o que estávamos falando, aconteceu após a leitura casual encontro à feição de uma sincronicidade junguiana - de um irônico poema juvenil, link recebido em minha caixa de correio eletrônico justamente no momento em que eu buscava traçar os primeiros esboços relacionais do almejado conceito. O texto, que chamou minha atenção pelo título 'Vida de escola', é de autoria da menina Clara Regina Oliveira, da cidade de Patrocínio do Murié, Minas Gerais:

\footnotetext{
Nesta vida de escola / muito se fala...

Nesta vida de escola / muito se quer...

Nesta vida de escola / muito se ensina...

Nesta vida de escola / pouco se aprende! ${ }^{6}$
}

Ao compartilhar suas impressões da vivência escolar, Clara expressa drasticamente a cisão percebida entre as muitas intenções de 'falar/querer/ensinar' e um resultado concreto de 'aprender' (a viver, será?). Esta não seria, igualmente, a 'nossa' questão, ainda que uma certa noblesse acadêmica nos obrigue a formulá-la de modos menos temerários?

Antes de prosseguir, devo explicações acerca do que entendo sobre a tarefa de construção de um conceito, as inspirações e vizinhanças do conceito de 'vida de escola' e suas origens imediatas e condições. Tomo de início o 'conceito de conceito' de Deleuze e Guattari (1992), como exposto em o que é a filosofia?: conceitos têm história, origem, contexto, percurso, mas são sempre 
singulares; são (segundo a terminologia dos autores) 'acontecimentos' e não essências; um conceito é sempre um emaranhado cujas condições geralmente encontram-se em outros conceitos, isto é, um conceito está sempre em devir; ${ }^{7}$ é sempre multiplicidade (de sons, cores, movimentos), embora nem toda multiplicidade seja conceitual; conceitos são "vizinhos que não delimitaram bem seus terrenos" e, por isso, não se pode conhecer exatamente a linha demarcatória entre o início de um e o término de outro: conceitos se mesclam e (às vezes) se confundem. Desse modo, segundo eles, "não há conceitos simples. Todo conceito tem componentes e se define por eles" (Deleuze e Guattari, 1992, p. 23). Conceitos são constituídos de partes, planos, relações. O conceito, enfim, remete sempre ao problema fundamental do eu e do outrem, este último entendido como a abertura a toda possibilidade, ao 'mundo possível', expresso e atualizado em uma linguagem.

Conceitos são criados. ${ }^{8}$ Para Deleuze e Guattari, a produção de conceitos seria a tarefa mesma da filosofia. Trata-se de uma atividade criativa, portanto, e criadora, uma vez que um conceito põe em marcha uma série de sentidos e enseja tantos outros novos conceitos. Entender adequadamente um conceito (como tal) requer sobretudo atenção a dois tipos ordinários de armadilhas: por um lado, um conceito não é nem a expressão da realidade nem um mero termo da língua, ainda que tratemos de um certo modo de apropriação do real, e, sim, pela língua e para além dela; por outro, não se trata nem de desvelar uma 'essência' nem de produzir listas taxonômicas, isto é, não se chega às coisas por alguma pretensa qualidade interna delas mesmas nem por meramente delimitá-las (como em um cercadinho) em relação a outras. Os extremos, se não oferecem propriamente perigo algum (a não ser, talvez, à consecução do sentido), aparentam ser de pouquíssimo interesse operacional, o que equivale a dizer: quase nada são capazes de explicar.

As 'vizinhanças' e inspirações do conceito de 'vida de escola' mais interessantes localizam-se, principalmente, nas ideias de 'mundo da vida' (Lebenswelt) propostas por Husserl (1970) ${ }^{9}$ e, adiante, Habermas (1987). Em Husserl, o mundo da vida aparece como uma dimensão de horizonte de experiências, como contexto cultural concreto a abrigar o ser no mundo. Vinculado à correlação entre a consciência e o mundo, o Lebenswelt precede tanto as construções científicas quanto as formulações metafísicas, expressando-se, assim, por "experiências pré-científicas originárias", construído a partir das formas sensíveis na experiência cotidiana (Zilles, 2001).

Segundo esse mesmo autor, o mundo da vida constitui a somatória das experiências vividas no interior de uma realidade rica e complexa, agindo ativamente na construção do indivíduo, constituindo-o em seu contexto histórico, linguístico e cultural, entre seus valores e princípios. O Lebenswelt, segundo ele, não é uma soma de objetos, mas o mundo do subjetivo do qual emerge toda a atividade humana (Zilles, 2001). 
Nessa trilha, Habermas (1987) entende o mundo da vida como blocos de modelos consentidos de interpretação, compromissos e práticas, situando-o em relação de oposição ao mundo do sistema. Sua Teoria do Agir Comunicativo o descreve como um contexto não problematizável, pano de fundo a propiciar processos que visem à consecução do entendimento. Para Habermas, o Lebenswelt, em seu sentido cotidiano (que é aquele que, no fundo, mais nos interessa), pode ser expresso como um lócus em que "os atores comunicativos situam e datam seus pronunciamentos em espaços sociais e tempos históricos" (Habermas, 1987, p. 136), sendo para estes impossível que se localizem de algum modo 'fora' dele. Assim, e segundo a construção de sua ética, o autor entende que o mundo da vida seria a esfera de reprodução simbólica, a dimensão da linguagem e das redes de significado que comporiam uma determinada visão de mundo, em relação quer aos fatos objetivos (marcados pelas normas sociais), quer aos conteúdos subjetivos do agir comunicativo. Nesse sentido, é importante mencionar ainda a ressonância dessas ideias com o trabalho de Paulo Freire e suas noções de 'leitura do mundo', 'leitura da palavra-mundo' e da oposição entre o que ele chama de uma 'educação bancária' versus uma 'educação dialógica' (Freire, 1992).

Por fim, apenas como procedimento metodológico (e por julgá-lo suficiente) visando à construção do conceito, parto de algumas definições selecionadas para expressar a compreensão dos autores da pesquisa sobre as escolas e centros formadores de saúde pública brasileiros. Tais formulações contêm elementos caros ao nosso conceito em gestação. Estes são os textos reproduzidos no relatório final da pesquisa (sobre a escola e a educação) que particularmente nos interessam:

Flecha e Tortajada destacam o fato de que a Escola tanto pode ser "um fator de transformação como de exclusão, mas não é uma instituição neutra nem uma instituição reprodutora" (Flecha e Tortajada, 2000, p. 29, apud Brasil, 2008, destaques no original).

[É preciso] compreender a educação através de elementos "dialeticamente complementares e contraditórios", mas que lhe conferem conteúdo: ideias pedagógicas, instituições pedagógicas, material pedagógico e ritual pedagógico (Cury, 1995, p. 87, apud Brasil, 2008, destaques no original).

[Escola é] uma instituição social perpassada pela dialética estabelecida entre o sistema e o mundo da vida e uma organização composta de vários mundos (Estevão, 2003, apud Brasil, 2008, destaques no original).

[Escola é um] espaço de intersecção de vários referenciais de ação pública, na linha do que outrora já prenunciáramos, ao entendê-la como organização fractalizada e multidiscursiva e simultaneamente como organização institucionalizada (Estevão, 2003). 


\section{Vida de escola e o mapa geral do conceito}

Assumo como ponto de partida para o conceito de vida de escola a noção grega de ethos, como o entende o helenista Henrique Murachco a partir dos textos aristotélicos. Sua leitura privilegia uma tríplice conjunção, incluídas as ideias de: 'lugar e pertencimento', em primeiro lugar - isto é, ethos como relacionado a uma origem e um enraizamento na própria physis; 'natureza e caráter', condição de existência vinculada a uma aesthetika; e ainda 'usos e costumes', formas de agir - escopo hodierno preponderante na expressão 'ética' - relacionadas a uma certa poiesis (Murachco, 2005). Por conseguinte, um mapa geral do conceito de vida de escola deve, nesse sentido, abrigar também uma 'física', uma 'estética' e uma 'poética' como componentes do ethos da escola viva. Neste ensaio, descreverei tão somente a primeira parte dessa tríplice construção, ou seja, a 'física' do conceito, que se expressa por meio de uma determinada estrutura relacional interna.

Algumas notas sobre os dois outros pontos de ligação são bem-vindas, no entanto. Em relação à compreensão do ethos da escola viva como 'natureza e caráter', refiro-me basicamente a uma 'estética do conhecimento' - em tudo diversa de uma teoria sociológica da cognição, devo pontuar - lembrando que não a entendo como única (ou mesmo a 'melhor') forma de construção de conhecimento, mas apenas uma modalidade hegemônica ocidental, devedora do percurso heleno-romano-judaico e estreitamente vinculada ao mundo hipermoderno em que habitamos (Lipovetsky, 2009). Tal estética é fundada na afecção, no contágio, na reação e no atrito, e tem como categorias principais as ideias de 'tempo' ('tempo presente', sobretudo), 'qualidade' e 'alegria'. Em outra ocasião, talvez, tenhamos oportunidade de abraçarmos com mais tempo e espaço essas concepções.

Quanto ao agir implicado na ideia de ethos como 'usos e costumes', será suficiente, por enquanto, notar que seu percurso implica as noções de intenção e intencionalidade - aliadas àquelas de vínculo e pertencimento - mas, sobretudo, de interdependência e autonomia. ${ }^{10}$ Nesse caso, é o movimento que está em jogo. Assim, podemos dizer que 'cada escola viva tem uma vida própria', que 'toda escola viva tem uma vida de escola', e que esta, por sua vez, define o que ela é (um 'acontecimento') e ainda o que ela espera ou o que dela se espera (um 'devir').

\section{Vida de escola, lugar e pertencimento}

Com base nas definições contidas no relatório final da pesquisa com as escolas de governo e apresentadas aqui, podemos gerar uma síntese interessante, afirmando que, por um lado, a escola é uma 'instituição social dialética' e, por outro, é uma 'organização complexa institucionalizada' localizada (e movendo-se) 'entre planos e dimensões'. Acrescentei ênfase ao termo 'entre' 
para ratificar um lugar importante da escola como notável mediadora e lugar de passagem (ponte, porta, escada, via) entre diferentes estados e modos de ser no mundo da vida.

A 'física' do conceito de vida de escola nos diz que esta é, antes de tudo, um 'lugar'. A expressão implica um (determinado) ponto de vista, uma certa perspectiva, uma 'posição'. Além disso, expressa a ideia de um território que, por sua vez, 'denota uma pertença e demanda um pertencimento' - este relacionado a uma decisão, e aquela a uma 'vinculação originária'.

Este lugar - em tudo especial e singular, dentre tantos outros - pode ser melhor definido como um ambiente de valores, como um espaço de vivências, como campo do embate organizado de ideias e práticas, como abrigo das novas gerações e como laboratório de incorporações tecnológicas. Cada um desses vários modos de ser no espaço do mundo da vida reflete uma dada qualidade necessária e esperada da escola, e demandaria muitas laudas para uma discussão detalhada. Creio ser capaz de resumir a todos - ou quase todos - reorganizando-os em torno de apenas 'três lugares-síntese'. As relações entre estes - e o que elas por si mesmas são capazes de gerar - devem evidenciar suficientemente a physika do conceito de vida de escola, isto é, sua primeira e mais abrangente - devido a seu caráter notadamente estrutural - dimensão.

Em primeiro lugar, a escola pode ser vista como um 'lugar de apreensão e síntese do real'. Movendo-nos ainda em torno da noção de Lebenswelt, entendo este 'real' como aquilo que nos afeta e nos provoca à reação, ao atrito do mundo em suas variadas dimensões e qualidades, ${ }^{11}$ ao cotidiano e concreto 'horizonte de experiências' (Husserl, 1970). Ou, segundo os gregos, como a própria physis que brota e (nos) aparece, mediada pela consciência. Tal lugar de apreensão e síntese assume a perspectiva de um observatório permanente da realidade. Os verbos essenciais desse lugar são 'atentar', 'atrair', 'absorver'.

Em segundo lugar, a escola é um 'lugar de estabelecimento de relações'. Isso implica um espectro de elementos muito mais numeroso e abrangente do que este ensaio é capaz de elencar. Apenas para situar meu argumento, porém, posso adiantar que o que está em jogo aqui é, por um lado, o reconhecimento e o respeito às diferenças de diversas ordens - o que exige esforços e recursos consideráveis - e, por outro, a assunção de (digamos, na falta de melhores palavras) compromissos sociais baseados principalmente na ideia de responsabilidade. ${ }^{12}$ Nesse lugar tem 'lugar', ainda - ao feitio de um eixo articulador -, a noção de 'agência' como entendida por autores que se dedicaram, nos últimos anos, a reposicionar as chamadas ciências sociais, redefinindo-as a partir da inclusão simétrica de elementos não humanos entre os humanos e dos modos pelos quais aqueles chegam a provocar, induzir e mesmo definir as ações destes últimos, em uma heterogênea rede de relações (principalmente Latour, 2005, e Law e Hassard, 1999). Os verbos desse lugar são, portanto, 'debater', 'falar/ouvir', 'dialogar', 'vincular'. 
Em terceiro lugar, a escola é um 'lugar de tradução'. A escolha do termo 'traduzir' advém, de início, de sua carga semântica etimológica. A palavra tem origens no latim traducere, que, por sua vez, é composto de trans ('além $\mathrm{de}^{\prime}$, 'para o outro lado', e ainda 'por sobre', 'de um lado para o outro, inteiramente') e ducere (literalmente 'conduzir', 'levar', 'guiar'). Traducere, portanto, tem seu sentido original ligado a um movimento de 'conduzir para o outro lado, através de'. Mas pensamos ainda nos sentidos de 'mediação criativa' e invenção atribuídos tanto pelos modernos teóricos da tradução literária como a ideia de 'transcriação' dos irmãos Campos (1977), por exemplo, e a tarefa-renúncia de Benjamin (2001) - quanto por autores vinculados a certas linhas da antropologia (Roy Wagner, 2010, entre outros) e das teorias sobre a construção do conhecimento científico (o já citado Bruno Latour, 2005).

Nesse sentido, o lugar da tradução diz respeito à compreensão da construção mesma do processo civilizatório, errático, errante, atravessando 'de um ponto a outro' a experiência humana. Os verbos desse lugar 'entre' todos os lugares são 'traduzir' (conduzir, a-través), 'mediar' (e, ao fazer isso, necessariamente produzir ou induzir o novo), 'criar'.

As relações entre esses termos - que, por sua vez, nominam 'lugares' geram 'caminhos', isto é, possibilidades singulares de movimento que, poderia dizer, formam o coração da potência da educação. Assim, a relação entre os lugares de apreensão e síntese do real e da tradução compõe a via da 'informação'. Entendo essa expressão com um sentido mais abrangente do que aquele que o uso comum atribui, isto é, não apenas como mera transmissão de dados, mas como produção de sentidos a partir da apreensão do real no encontro com a consciência reflexiva.

Cabe lembrar que o sentido original de 'informar' traz para a expressão latina formare, em seu prefixo in, a ideia de 'passagem a um novo estado', 'resultado de um movimento', e 'movimento de fora para dentro'. O sentido, portanto, de in-formar seria algo como 'formar-dentro', 'dar forma' - segundo a etimologia de formare - 'a partir de um certo movimento'. Cícero (106-43 a.C.) usa informare como quase um sinônimo de 'educar' ou 'instruir': 'formar no espírito' e 'formar o espírito'. Não iría tão longe, no escopo deste ensaio, mas retenho a noção de 'produzir uma (outra) forma a partir de um movimento de fora para dentro'. Por essa razão, a via da informação (no âmbito da vida de escola, necessário manter em mente) requer e pressupõe uma certa desconstrução e problematização do real, com potencialidade para gerar o que eu chamaria de 'inconformismo produtivo'.

A seguir, a via formada pelas relações entre a apreensão e síntese do real e o lugar do estabelecimento de relações pode chamar-se, a meu ver, 'formação', expressando igualmente sentidos mais amplos do que os usualmente apreendidos quando ouvimos, por exemplo, frases do tipo 'formar pessoas'. Embora sem descartar totalmente os primeiros sentidos do latim formare - 'dar forma 
segundo uma determinada fôrma'-, ${ }^{13}$ é desejável alargar um pouco o âmbito da expressão de modo que ela também - a exemplo de informação - venha a 'enformar' as ideias de construção do novo e de processos criadores, isto é, de 'produção não conformada'.

Por fim, vemos que a via criada a partir do encontro entre os lugares da tradução e do estabelecimento de relações é a 'transformação'. Essa via comporta as ideias de mudança, alternância, transporte de uma forma a outra, passar além, para o outro lado, ultrapassar uma 'fôrma', mudar de forma a-través. Vários autores (entre eles McLuhan, 1964; Wagner, 2010; Latour, 2005; Deleuze e Guattari, 2004) sugerem que as ideias de 'informação', 'formação' etc. são úteis apenas como distinção didática e categórica, uma vez que, na verdade, o que existe de fato é somente 'trans-formação' em seus diversos níveis. Tal operação é sempre simétrica, ou seja, aquilo que agencia a transformação é também transformado no e pelo próprio ato de transformar.

O percurso das três vias, por seu turno (e operando uma espécie de retorno, ou dobra), vem finalmente proporcionar a emergência de certos tipos de 'sujeitos' (personalidades morais e autônomas), aqui distintos entre si apenas visando à clareza didática. $\mathrm{O}$ encontro das vias 'informação' e 'formação' gera potencialmente o 'sujeito cognitivo' - no âmbito relacionado ao lugar da apreensão e síntese do real. É a este sujeito que a escola tradicionalmente dedica maior atenção e esforços, isto é, a 'formar' sujeitos capazes de 'conhecer', 'aprender', reunir e fazer uso de 'informações'. Entendo que a chamada 'educação bancária', segundo as palavras de Paulo Freire, expresse essa única face de uma reduzida, reprimida e achatada ideia de escola, lamentavelmente ainda em voga hoje em dia.

A esquina da 'formação' com a 'transformação' é capaz de gerar potencialmente um 'sujeito social', no âmbito do lugar das relações. Se é possível ensinar a virtude e os valores (querela que remonta à antiguidade grega e sobre a qual me eximo de emitir opiniões), é nessa esquina e nesse lugar que isso acontece, ou deve acontecer. Por sujeito social podemos igualmente entender um sujeito político, entre os seus, imerso e comprometido com seu contexto sociocultural, condicionado por e condicionando o socius ao qual está integrado.

E assim chegamos ao encontro entre as vias 'informação' e 'transformação', relacionado ao lugar da tradução e que gera, por sua vez, um 'sujeito criativo', aquele capaz de produzir plenamente o novo, a invenção, o salto adiante. O sujeito criativo estaria, forçando uma analogia com as teorias de evolução, no lugar do 'acidente' que se oculta no seio mesmo da necessidade e ocasionalmente a ultrapassa e redefine. Assim, temos três 'lugares' (apreensão e síntese do real, estabelecimento de relações, tradução), cujas relações produzem três 'vias' (informação, formação, transformação), e estas, dobrando-se, são capazes de gerar três 'sujeitos' (cognitivo, social, criativo). 
Cada um desses termos depende dos demais e os condiciona, e não se pode prescindir de nenhum deles na conformação, ao fim e ao cabo, da física da 'escola viva', imagem estrutural e diagramática do conceito de 'vida de escola'. Em suas relações internas, portanto, este pode ser expresso da seguinte maneira (Figura 2):

Figura 2

Relações da escola viva

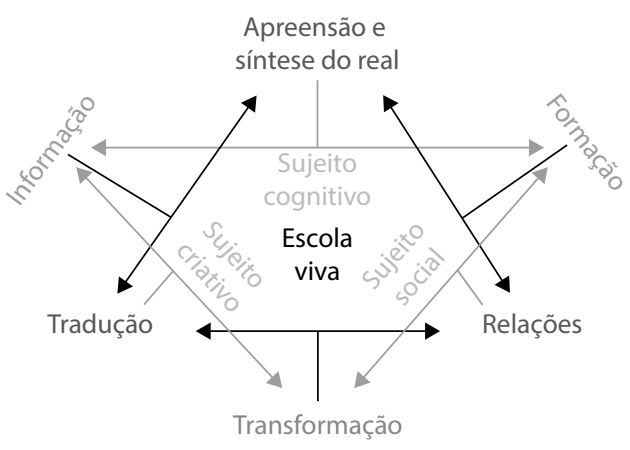

Fonte: $\mathrm{O}$ autor.

\section{Relações potenciais entre a comunicação e a educação}

A intromissão da palavra 'potenciais' para qualificar as relações entre esses grandes campos de saberes e práticas serve para nos advertir que tais relações não estão dadas. Parece-nos suficiente pincelar alguns componentes capazes de 'ligar' tais campos, sendo que, ao fazê-lo, terminam por redefini-los e criar até mesmo novos e mais abrangentes campos (quiçá mais úteis) como parte da criativa atividade de tradução.

Costuma-se definir a comunicação a partir de seu étimo latino, segundo o qual communicare tem o sentido principal de 'tornar-comum', isto é, proporcionar que algo íntimo e privado (um pensamento, uma ideia, uma sensação) seja igualmente percebido e apropriado por outros. 'Comunicar', de fato, é 'tornar-comum', ultrapassar - com maior ou menor sucesso - a barreira do eu e do outro. As lições de Habermas (1987) nos mostram que para que tal fato se suceda é necessário que haja uma 'pretensão de verdade' inercial, constitutiva do ato mesmo de comunicar. Ou seja, é preciso um acordo subjacente a todo discurso de que o outro esteja dizendo a verdade e que o outro suponha igualmente que eu esteja dizendo a verdade. De outro modo, a comunicação seria impossível. Lembro que tal acordo não incide necessariamente sobre a 
verdade ou falsidade do discurso em si - o mentiroso vale-se disso do mesmo jeito, uma vez que mesmo a mentira é uma forma de comunicação -, mas somente sobre o pressuposto das intenções mais íntimas dos enunciadores.

O mais alto grau de, digo, sucesso de um ato comunicativo é o que Habermas denomina 'dialogia', isto é, quando os enunciadores compreendem adequadamente os discursos uns dos outros, situam-se como portadores de uma razão e de um agir comunicativo em relação aos outros e, por fim, ao acolherem os diversos argumentos, entram em concordância voluntária acerca de seus sentidos. A palavra que culmina o processo dialógico é 'consenso'.

Com base em tal esboço da comunicação, percebemos que ela e o que tenho chamado até agora de educação poderiam vir a constituir uma espécie de conceito conversível, segundo o qual digo que, num certo sentido, 'educar é comunicar' e 'comunicar é educar'. Sei que tal distinção de práticas e disciplinas $^{14}$ é recente e refere-se aos tempos modernos. A antiguidade helênica não conhecia tais distinções, e um bom exemplo é a palavra grega por excelência significativa da educação do homem pleno: paideia. Sócrates era conhecido por seu discipulado 'maiêutico', baseado na premissa de que ensinar é simplesmente dar à luz o conhecimento que já existe em cada homem, por meio de um processo dialógico e dialético. Mutatis mutandis, poderíamos dizer que em Sócrates mesclar-se-ia o que hoje entendemos por 'educação dialógica' e uma 'comunicação plena' (Jaeger, 2001).

Se tomamos 'comunicar' como 'tornar-comum', podemos consequentemente tomar 'educar' por 'tornar-incomum', ressaltando o caráter (ideal) das práticas educativas de produzir diferenças, qualidades, singularidades e, ao final, autonomia. Todos esses atributos estão ligados à aquisição de uma certa forma de estar no mundo com o máximo possível de liberdade (de pensar, expressar-se e agir) por si próprio, baseado em suas próprias normas internas e decisões (autos+nomos). O binômio ganha ainda mais força quando reparamos que é impossível haver educação sem que, antes, algo seja compartilhado, 'feito-comum'. E que, inversamente, é absolutamente desejável que aquilo que - a se tomar o sentido dialógico de uma genuína 'razão comunicativa'-15 entendemos por 'comunicar' deve levar à consecução de mais e melhores formas de estar no mundo com autonomia, isto é, tal tipo de comunicação supõe as qualidades de um processo educativo e, nesse caso, 'formador'.

Desse modo, uma relação consciente entre os campos da comunicação e da educação geraria uma 'educação comunicativa' - na qual a comunicação aportaria à educação os saberes e práticas próprios da dialogia e da geração de consensos - e uma 'comunicação pedagógica', na qual a educação aportaria aos processos de comunicar os atributos da construção de autonomia. 'Comunicação pedagógica' e 'educação dialógica' devem, assim, ser entendidas como (apenas um único) conceito novo e operacional, e não como mera adjetivação dos processos comunicativo ou educativo. 
Ao assumir sua qualidade comunicativa, a educação é levada a perceber que falhas tidas como 'do modelo pedagógico' ou de 'didática' são, muitas vezes, problemas de comunicação. A educação costuma enxergar a comunicação exatamente da forma como ela se apresenta ao senso comum, como simples meio e instrumento, algo responsável por 'transmitir' um certo 'conteúdo' de um emissor a um receptor. A dialogia, nesse caso, não se constitui apenas como resultado de uma prática social instintiva e corriqueira, mas sim de um 'saber', e um saber intrínseco à prática (profissional) da comunicação.

Se a educação abriga em si um forte componente de valor, é preciso desconstruir esse componente em relação à comunicação. Se uma 'boa educação' tem a intenção de tornar melhores o ser humano e a sociedade, uma 'boa comunicação' não contempla necessariamente esse objetivo. Entende-se, simplesmente, que algo foi tornado-comum com sucesso. A compreensão (e, para alguns, a subsequente disposição à ação) é o principal valor da comunicação, e não um suposto incremento à autonomia. Ao contrário, percebemos claramente - pela História e pela vida cotidiana - que muitas práticas de comunicação bem sucedidas são formas de encapsulamento do ser, de dominação, de doutrinação, de subjugo do pensamento (vejam-se, por exemplo, as campanhas publicitárias, as propagandas nacionalistas, os vários fundamentalismos, religiosos ou não, e até mesmo alguns modelos educacionais). A educação aporta (ou deve aportar) à comunicação o seu principal valor, o desenvolvimento da autonomia. ${ }^{16}$

Assim, o binômio 'comunicação pedagógica, educação dialógica' ou 'comunicativa' não configuraria uma 'terceira coisa', uma imposta síntese entre dois campos de saber e fazeres, tampouco poderia ser tratado como mera ligação funcional de dois blocos estanques. Ao contrário, é a proposta de uma nova maneira de relacionamento entre dois campos, na qual cada um aportaria ao outro seus saberes próprios - e se deixaria generosamente apropriar pelo outro. É uma proposta de relacionamento que potencializa as práticas (educativas, comunicativas) em direção à plenitude de suas missões e sentidos sociais.

Por fim, caso nos dispuséssemos a contemplar nesse quadro o campo da gestão - tão intrinsecamente vinculado às ideias de vida de escola -, diria que esta área trataria primordialmente de dar concretude às ações pensadas. Se a comunicação é responsável por 'tornar-comum' e a educação por 'tornar-incomum', veria a gestão como ocupando-se de 'tornar-real', isto é, de transformar em ações eficazes e corretas os desenhos, desejos e esboços do pensamento (desígnios, design). Assim, aportando o que genericamente estou chamando de design à comunicação e à educação, o campo da gestão conformaria uma 'comunicação e uma educação produtiva' ${ }^{17}$ Ao se apropriar, por sua vez, dos atributos desses dois outros campos, a própria área da gestão transforma-se em uma gestão dialógica (ou comunicativa) e pedagógica. ${ }^{18}$ 
Um esquema geral dessas relações pode ser esboçado da seguinte maneira (Quadro 1):

Quadro 1

Relações entre comunicação, educação e gestão

\begin{tabular}{|l|l|l|}
\hline \multirow{2}{*}{$(x)$} & Comunicação pedagógica & A educação aporta à comunicação o valor da 'autonomia' \\
\cline { 2 - 3 } & Educação dialógica & A comunicação aporta à educação o valor da 'dialogia' ('consenso') \\
\hline \multirow{2}{*}{ (y) } & Gestão dialógica & A comunicação aporta à gestão o valor da 'dialogia' ('consenso') \\
\cline { 2 - 3 } & Comunicação produtiva & A gestão aporta à comunicação o valor do 'desígnio' \\
\hline \multirow{2}{*}{ (z) } & Educação produtiva & A gestão aporta à educação o valor do 'desígnio' \\
\cline { 2 - 3 } & Gestão pedagógica & A educação aporta à gestão o valor da 'autonomia' \\
\hline
\end{tabular}

Fonte: $\mathrm{O}$ autor.

Unindo-se, finalmente, esses binômios no âmbito da 'vida de escola', percebemos que uma 'escola viva' teria como tarefa essencial: 'tornar-incomum o que é comum'; 'tornar-comum o que é incomum'; e 'tornar-real... para o bem comum'.

Nos encontros da Rede de Escolas e Centros Formadores em Saúde Pública, os dirigentes das escolas costumam se remeter a uma série de expressões muito significativas e que, a partir de vários estados do país, constituiriam uma espécie de diagnóstico popular da situação da educação em saúde. Tais palavras apontam, ampliando o espectro da dimensão escolar, para uma 'vida de escola' situada no campo da saúde coletiva, no qual desfilam “desejos, projetos, uma certa episteme, conflitos e contradições próprios do 'mundo da vida da saúde coletiva'" ${ }^{19}$ No âmbito estrito de nosso ensaio, as frases traem o pessimismo dos professores, incapazes de ver solução ou melhoria para esse estado:

- “Os alunos 'escorregam' como água, passam..." - a sentença indica que há movimento, mas sem 'autonomia'.

- "A escola 'abdicou do seu lugar' ..." - há posição, mas sem 'lugar'.

- "A vida caminha, a escola 'sucumbe'..." - há um caminho, mas sem 'mudança'.

- "A escola está 'descolada da realidade'..." - está no mundo, mas sem 'vínculo'.

- “Todos pensam igual, fazem igual. Há uma 'profunda superficialidade' ..." - há reprodução, mas não 'diferença'.

- "A escola não desperta interesses, é 'desinteressante'..." - há razão sem 'sedução'.

- "Atualmente, só se fala em 'crise'..." - há crítica, sem 'alegria'.

Notamos, por uma via negativa - adiantando elementos constituintes de uma poietika do conceito, relacionada aos sentidos de ethos como usos 
e costumes -, que são justamente essas palavras as melhores expressões da escola-viva, ideias-chave de vida de escola: 'autonomia', 'lugar', 'mudança', 'vínculo', 'diferença', 'sedução', 'alegria'.

Com esse jogo gestaltiano de palavras, e deixando-as 'flotar' no ar como balões de gás, sujeitas por enquanto aos vários ventos do sentido e livres dos quadros de análises ou rigores hermenêuticos, concluo este ensaio. Se o iniciei com uma obra de arte sobre tela, faço igual ao encerrá-lo (Figura 3). Eis o cachimbo de Magritte, seguido de comentários de Foucault (2008).

\section{Figura 3}

A traição das imagens, pintura de René Magritte (1929)

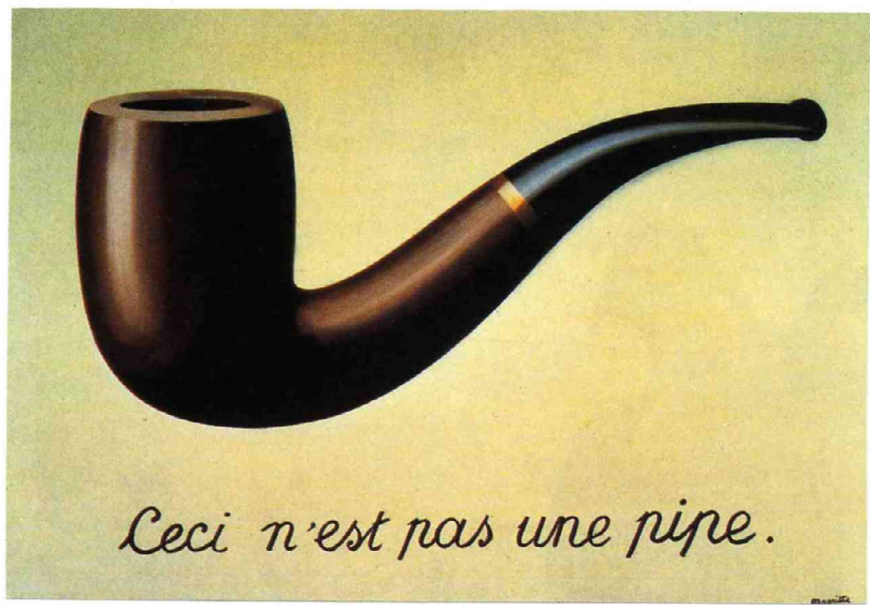

Nada de tudo isso é um cachimbo; mas um texto que simula um texto; um desenho de um cachimbo que simula o desenho de um cachimbo; um cachimbo (desenhado como se não fosse um desenho) que é o simulacro de um cachimbo (desenhado à maneira de um cachimbo que não seria, ele próprio, um desenho). Sete discursos num só enunciado, para nos lembrar que... (Foucault, 2008).

...isto aqui 'não é' um cachimbo, do mesmo modo que o conceito de vida de escola (em seus múltiplos discursos aqui expostos) 'não é' a vida de escola, do mesmo modo que o caminho somente se faz ao caminhar. No entanto, o caminhante precavido há de ter um mapa e uma bússola, e há de saber de onde está saindo e aonde quer chegar... (Foucault, 2008). 


\section{Financiamento}

Este suplemento “Educação e Trabalho em Saúde: diálogos e experiências no Brasil e em Portugal" foi realizado com apoio da Coordenação de Aperfeiçoamento de Pessoal de Nível Superior (Capes) - Código de Financiamento 001; e do Departamento de Pesquisa em História das Ciências e da Saúde da Casa de Oswaldo Cruz (Depes/COC/Fiocruz, 6151000000). Todos os autores declaram que não há conflito de interesses.

\section{VIDA DE ESCUELA: COMUNICACIÓN EN LA RED DE ESCUELAS DE SALUD PÚBLICA BRASILEÑAS}

Resumen Este estudio tuve como objetivo resaltar las relaciones entre los conceptos más preciados de la educación, sobre la base de la intersección entre los campos profesionales de la educación, de la comunicación y de la administración orientados hacia la Salud Pública. Para hacer posible tales síntesis, se invierte en la creación del concepto 'vida de escuela', volviendo a los documentos y a las actividades en el ámbito de la Red de escuelas de Salud Pública brasileña, donde esa expresión habría surgido esperando definiciones y vecindades apropiadas. Por medio de ese concepto, se discuten algunos de los aspectos y mediaciones más fundamentales a las concepciones modernas de Educación y al papel de las escuelas de salud en nuestro país.

Palabras clave educación; educación sanitaria; comunicación; formación para salud pública.

\section{Notas}

${ }^{1}$ Para ser mais preciso, os termos mais adequados a esta referência seriam 'pelos ideais do Esclarecimento', mantendo em mente a obra de Adorno e Horkheimer (1985).

${ }^{2}$ Nesse trabalho, Singer, ao questionar a dominação humana sobre os animais, cunha a expressão 'especismo' (ressonante, por sua vez, com 'sexismo' e 'racismo'), de modo a sustentar que não há legitimidade nos argumentos de exploração da vida de outros seres sencientes, além da suspeitosa invocação de uma superioridade natural de nossa 'espécie humana'. Esse argumento, como ele recorda, é análogo àqueles que, em épocas passadas, 'justificaram' a escravidão de negros e indígenas, muitas formas de exterminação étnica e até mesmo a imposta submissão das mulheres aos homens. Visando a fins semelhantes, proponho também o uso da expressão 'humanicismo' (ressonante com 'cientificismo', por exemplo) para denotar um desvio dogmático e sutil, mas facilmente perceptível nos dias de hoje, das várias vertentes dos ideais humanistas que, desde a Renascença, atravessam nossas sociedades, nossas artes e nossas ciências.

${ }^{3}$ Sobre esse interessante conceito, e no ambiente relacionado às tecnologias de informação e comunicação (TICs) e à área da saúde, sugiro uma passada de olhos no trabalho de Luiz Castiel e Paulo Vasconcellos-Silva (2006), Precariedades do excesso.

${ }^{4}$ Muitos séculos separam a necesse do general romano e a exatidão de Petrarca, mas quem sabe de um, de outro? Pessoa toma a frase para si, para casá-la a si, e a explica segundo a necessidade, segundo a pulsão de criar. Para tornar a vida grande, e de todos, ainda que a perca. Pois não é justamente para isso que nos metemos num navio? 
${ }^{5}$ Uma das hipóteses etimológicas para essa expressão defende a ideia de que ela provém da união dos termos gregos théos (deus) e oráo (ver, olhar). Theoría estaria relacionada, assim, à espécie de contemplação dos deuses. Desse modo, entendemos a razão de os espectadores das competições dramáticas, durante as Dionisícas, bem como de os espiões de guerra, infiltrados em cidades inimigas, serem ambos denominados theóros, aquele que observa sem intervir.

${ }^{6}$ No site: <http://www.pucrs.br/mj/poema-estudante-23.php>, acessado em 10/3/2011.

${ }^{7} \mathrm{O}$ que nos remete à ideia da 'semiose infinita' peirceana, noção que nos cabe perfeitamente.

${ }^{8 ' C r i a r}$ conceitos' parece, no entanto, algo diferente de 'conceituar'. Enquanto o primeiro é uma atividade produtora e criativa, o segundo trata, ao contrário, de uma espécie de 'encobrimento' (Paz, 1996).

${ }^{9}$ Esta com importantes ressonâncias em Schütz (1972) e Wittgenstein e sua lebensform (1975).

${ }^{10}$ Sobre esse ponto, é notável a coincidência com o pensamento de Paul Ricouer, quando ele diz que "a ética só é completa como política porque é o conjunto dos homens, é a comunidade que é orientada para o 'bem viver"” (Ricouer, 2002, p. 53).

${ }^{11}$ Esta dimensão refere-se, em outros termos (semióticos), à secundidade peirceana, à esfera sígnica das afecções, a arena da existência cotidiana (Peirce, 1931, p.58).

${ }^{12}$ Refiro-me sobretudo às formulações de Hans Jonas (2006).

${ }^{13}$ 'Dar forma a algo', 'configurar', 'modelar'. O substantivo que dá origem ao verbo formare é 'forma', do latim forma. Se a grafia é idêntica, o sentido nem tanto. Desta palavra, derivaram-se para o português 'forma' e 'fôrma', distinção que não existe no latim. Forma tem o sentido primário de 'modelo, molde', e somente de modo figurado 'tipo ideal'. A palavra latina era utilizada num contexto bem menos abstrato do que o nosso: forma era o recipiente usado para a cunhagem de moedas e de utensílios de metal.

${ }^{14}$ A própria palavra 'disciplina' é derivada dos radicais latinos disc, doc, relativos ao ensino e à aprendizagem, precedidos do prefixo dis, que expressa separação, corte, dissensão. Ou seja, e muito rudemente: 'ensino por partes separadas'.

${ }^{15}$ Uma vez que a tomada de uma 'razão estratégica' poderia levar a dominação e doutrinações de toda espécie, quer pela sedução, quer pela violência.

${ }^{16}$ É preciso lembrar que, especificamente nesse caso, falamos de uma espécie de educação moderna, fundada sobre as bases do individualismo capitalista (do qual sequer as experiências socialistas lograram escapar). Ficam de fora desse quadro várias outras formas de educação relacionadas a outras realidades socioculturais não ocidentais, principalmente aquelas baseadas em concepções diversas da pessoa, da comunidade humana e do mundo. 
${ }^{17}$ Durante a confecção deste artigo, diversas palavras surgiram para ilustrar essa qualidade que a gestão aportaria às outras áreas. Pensou-se, por exemplo, em uma comunicação/educação 'estratégica', 'orientada', 'gerativa', 'organizada'. Cada uma dessas palavras traz em si uma carga semântica difícil de desconstruir no breve espaço de que disponho. Optei, finalmente e por enquanto, por utilizar o termo 'produtiva', para expressar simplesmente o ato poiético de 'tornar-real'.

${ }^{18}$ Não é necessário nem pertinente avançar nessas considerações aqui, mas sabemos que há, atualmente, uma vasta e substancial literatura acerca da gestão dialógica (ou coletiva, ou democrática, ou compartilhada), cujos pressupostos são hoje em dia geralmente expressos pela palavra 'governança'.

${ }^{19}$ De comunicação pessoal, inserida como comentário ao texto, de um dos pareceristas desta publicação. Optei por registrar sua sugestão e textualmente parte de suas palavras por considerá-las bem-vindas, pertinentes e enriquecedoras do ponto em questão. 


\section{Referências}

ADORNO, Theodor; HORKHEIMER, Max. Dialética do esclarecimento. Rio de Janeiro: Zahar, 1985.

BENJAMIN, Walter. Die Aufgabe des Übersetzens: a tarefa-renúncia do tradutor. In: Benjamin, Walter. Clássicos da teoria da tradução. v. 1. Florianópolis: Universidade Federal de Santa Catarina, 2001.

BRASIL. Ministério da Saúde. Secretaria de Gestão do Trabalho e da Educação na Saúde. Fundação Oswaldo Cruz. Escola Nacional de Saúde Pública Sergio Arouca. Pesquisa nacional de escolas de saúde pública - relatório final: inovações na educação em saúde pública com diálogo e parceria. Rio de Janeiro: MS/SGTES/ Ensp, 2008.

CAMPOS, Haroldo. A arte no horizonte do provável. São Paulo: Perspectiva, 1977.

CASTIEL, Luiz D.; Vasconcellos-Silva, Paulo R. Precariedades do excesso: informação e comunicação em saúde coletiva. Rio de Janeiro: Editora Fiocruz, 2006.

CURY, Carlos R. J. Educação e categorias. In: Cury, Carlos R. J. Educação e contradição. São Paulo: Cortez, 1995. p. 53-85.

DELEUZE, Gilles; GUATTARI, Félix. O que é a filosofia? São Paulo: Editora 34, 1992.

DELEUZE, Gilles; GUATTARI, Félix. Mil platôs: capitalismo e esquizofrenia. Rio de Janeiro: Editora 34, 2004.

ESTEVÃO, Carlos A. V. Organizações educativas, justiça e formação. In: FERREIRA, Naura S. C. (org.). Formação continuada e gestão da educação. São Paulo: Cortez, 2003. p. 219-240.

FLECHA, Ramón; TORTAJADA, Iolanda. Desafios e saídas educativas na entrada do século. In: IMBERNÓN, Francisco (org.). A educação no século XXI: os desafios do futuro imediato. Porto Alegre: Artmed, 2000. p. 21-36.
FOUCAULT, Michel. Isto não é um cachimbo. São Paulo: Paz e Terra, 2008.

FREIRE, Paulo. Extensão ou comunicação. Rio de Janeiro: Paz e Terra, 1992.

HABERMAS, Jürgen. The theory of communicative action. v. 2: Lifeworld and sistem: a critique of functionalist reason. Boston: Beacon Press, 1987.

HUSSERL, Edmund. The crisis of European sciences and transcendental phenomenology: an introduction to phenomenological philosophy. Evaniston: Northwestern University Press, 1970 [1936].

JAEGER, Werner. Paideia: a formação do homem grego. São Paulo: Martins Fontes, 2001.

JONAS, Hans. O princípio da responsabilidade. Rio de Janeiro: Contraponto, 2006.

KANT, Immanuel. Lógica. Rio de Janeiro: Tempo Brasileiro, 1982.

LATOUR, Bruno. Reassembling the social: an introduction to actor-network theory. Oxford: Oxford University Press, 2005.

LAW, John; Hassard, John. Actor network and after. Oxford: Oxford, University Press, 1999.

LIPOVETSKY, Gilles. O império do efêmero. São Paulo: Companhia das Letras, 2009.

McLUHAN, Marshall. Understanding media: the extensions of man. New York: McGraw-Hill, 1964.

MORIN, Edgar. A cabeça bem feita: repensar a reforma, reformar o pensamento. Rio de Janeiro: Bertrand Brasil, 2004.

MURACHCO, Henrique. O sentido de 'ethos' de Homero a Aristóteles. Comunicação apresentada em mesa-redonda da IV Semana Filosófica, João Pessoa, 2005. 
RICOUER, Paul. O único e o singular. São Paulo: Fundação Editora da Unesp, 2002.

PAZ, Octavio. Sombras de obras: arte y literatura. Barcelona: Editorial Seix Barral, 1996.

PEIRCE, Charles S. The collected papers of Charles Sanders Peirce. Charles Hartsforne e Paul Weiss, eds (v. 1-6) e A. W. Burks. Ed. (v. 7-8). Cambridge: Harvard University Press, 1931, p. 58.

RYDER, Richard. Victims of science: the use of animals in research. London: Centaur Press, 1975.

SANTOS, Boaventura S. A universidade do século $X X I$ : para uma reforma democrática e emancipatória da universidade. São Paulo: Cortez, 2004,

SANTOS, Boaventura S. Para além do pensamento abissal: das linhas globais a uma ecologia dos saberes. São Paulo: Cebrap, 2007. (Novos Estudos Cebrap 79).
SCHÜTZ, Alfred. Fenomenologia del mundo social: introducción a la sociologia compreensiva. Buenos Aires: Editorial Paidos, 1972.

SERRES, Michel. Polegarzinha. Rio de Janeiro: Bertrand Brasil, 2013.

SINGER, Peter. Libertação animal. Porto Alegre: Lugano, 2004.

WAGNER, Roy. A invenção da cultura. São Paulo: Cosac-Naify, 2010.

WITTGENSTEIN, Ludwig. Investigações filosóficas. São Paulo: Abril Cultural, 1975.

ZILLES, Urbano. Os conceitos husserlianos de 'Lebenswelt' e teleologia. In: OLIVEIRA, Nythamar F.; SOUZA, Ricardo T. Fenomenologia hoje: existência, ser e sentido no alvorecer do século XXI. São Bernardo do Campo: Fenpec, 2001. p. 511-520. 